\title{
LIMITED NETWORK CONNECTIONS AND THE DISTRIBUTION OF WAGES
}

\author{
Kenneth J. Arrow \\ Ron Borzekowski* \\ Stanford University $\quad$ Federal Reserve Board
}

August 18, 2004

\begin{abstract}
It is well-known that $50 \%$ or more of all jobs are obtained through informal channels i.e. connections to family or friends. As well, statistical studies show that observable individual factors account for only about $50 \%$ of the very wide variation in earnings. We seek to explain these two facts by assuming that the linking of workers and firms is mediated by limited network connections. The model implies that essentially similar workers can have markedly different wages and further that the inequality of wages is partly explained by variations in the sizes of workers' networks. Our results indicate that differences in the number of ties can induce substantial inequality and can explain roughly $15 \%$ of the unexplained variation in wages. We also show that reasonable differences in the average number of links between blacks and whites can explain the disparity in black and white income distributions.
\end{abstract}

\footnotetext{
${ }^{*}$ The authors thank the participants at the 2000 Stanford Institute in Theoretical Economics as well as members of the MacArthur Network on Social Interactions and Economic Inequality for their comments and feedback. Funding for this work was graciously provided by the MacArthur Foundation while both authors were at Stanford University. The views expressed in this paper are those of the authors and do not necessarily reflect those of the Board of Governors of the Federal Reserve System or its staff.
} 


\section{Introduction}

This study brings together two somewhat different economic questions. The first is the difficulty of explaining the distribution of income, in particular, wages. In a competitive world, wages should depend on worker characteristics (given the prices of outputs), however, a wide variety of statistical studies show that observable individual factors account for a limited part of the very wide variation in earnings. Known supply factors such as education, inherited abilities, or family characteristics, explain only about $50 \%$ of the existing variation in wages (see most notably Jencks et al. (1972)).

The second concerns the nature of the labor market or, rather, the extent to which the institutions that govern the allocation and reward of labor can properly be called a market. The typical image of a market in economic theory or even in common parlance requires, in effect, connections of all buyers with all sellers. Out of equilibrium, with buyers and sellers making varying offers, a seller can choose among buyers and vice versa. With totally standardized goods and complete information about prices, each seller will seek out the highest-paying buyer and each buyer the lowest-charging seller, so that the market will quickly come into equilibrium.

If goods, in our case, workers' skills, are thoroughly standardized but price information is not free, a standard approach has been to assume random but limited or costly search. On the other hand, in a competitive world with no information barriers but where workers' productivities vary according the firms for which they work, each individual would be working for the firm at which he or she is most productive. If, further, there is a number of firms at which any given worker has the same maximum productivity, then competition among them will drive the wage up to productivity. In fact, of course, the informational demands of such a system are impossible to meet.

In this paper, we raise a different combination of these questions, one more appropriate to the labor market. First, workers' productivities are not standardized but vary by firm. Second, the information channels are limited, but they are given, not objects of choice. We then assess whether the modified competitive equilibrium under these assumptions (limited connections and firm-specific productivities) gives some insight into the extent of the distribution of wages.

Let us start with some well-known facts about the labor market. Approximately $50 \%$ of all 
jobs are obtained through informal channels i.e. connections to family or friends. ${ }^{1}$ This proportion appears slightly lower for blacks than for whites (Holzer 1987, Green, Tigges and Diaz 1999). Further, workers who have found their jobs in this way are less likely to quit and show higher overall job satisfaction, providing some evidence that these links improve the quality of the employee-job match (Datcher 1983, Simon and Warner 1992).

Thus, the opportunities of individual workers are limited by the extent to which they have connections with firms. This fact, by itself, will give rise to income inequality even if all individuals are fundamentally the same, though not the same in all jobs. With limited connections, an individual worker will not find the job for which he or she is best suited. As a result, inequality may well appear in a model with limited connections due to the randomness of the connections. This stands in contrast to a neoclassical model with perfect matching of workers to jobs. If all workers are statistically the same, that is, have the same distribution of productivities over different firms, though not the same at each firm, then all workers would have the same wage (equal to their highest productivity).

Further suppose that different individuals have different degrees of connection to the economy. Then workers with different numbers of links will on the average have different incomes and, it would be expected that the most highly connected workers would have the highest incomes (though there might be a variance). Hence, variability in the numbers of links will contribute to income inequality in a way additional to that of the variables which explain fundamental ability to supply goods.

To formalize this notion, we develop and present a simple model of the job acquisition process that explicitly accounts for the role of network connections. In this sense, we join the small but growing economics literature that models the role of social networks in labor markets. The earliest studies, by Staiger (1990) and Montgomery (1992), examine how employment, turnover and wages vary with the source of one's job. Taking different approaches, Montgomery(1991, 1994), Krauth (2001), and Calvo-Armengol and Jackson(2003b, 2003a) more explicitly focus on how equilibrium outcomes vary with the structure of these networks.

\footnotetext{
${ }^{1}$ The classic study is that of Granovetter (1974). The earlier literature goes back to Schweinetz (1932), and includes Myers and Shultz (1951), Rees (1966), Rees and Shultz (1970), and others. An extensive list of 24 relevant U.S. studies can be found in Bewley (1999). For evidence on similar patterns in international data, see Pistaferri (1999).
} 
In contrast, we focus on the chance elements introduced by the limited number of connections and by the variability of the numbers of connections across workers. The model assumes that workers are equally able on the average, though of course their productivities at specific firms vary. How many connections they have and which firms they are connected to are taken as random variables. Using numerical simulations, we generate wages for these workers as well as the resulting wage distributions in the population and analyze the extent to which differences in the number of links contribute to inequality. We also make a preliminary stab at examining whether it is conceivable that the differences in the black and white income distributions could be explained largely by average differences in the degree of connection.

Our results indicate that differences in the number of ties can induce substantial inequality and can explain $15-20 \%$ of the unexplained variation in wages. We also show that reasonable differences in the average number of links between blacks and whites can explain the disparity in black and white income distributions. The model predictions for firm profits, and for the number of jobs found by informal means are both higher than real world values, yet the overall results seem promising and support the argument for the explicit inclusion of an individual's information network as a major component of social capital.

\section{Model}

To formalize the role of social networks, we offer a simple static model of the job acquisition process. The model posits a large number of workers indexed by $w$ and a set of firms indexed by $f$. We first describe the workers, then the firms.

\subsection{Workers}

In this model, workers possess two important qualities; their ability to produce output and their social network. In order to focus on the connection between networks and inequality, we assume that all workers have the same ability (mean productivity) yet their productivities vary across firms. More precisely, each worker $w$ has ability $a_{w}$, although these are assumed to be the same for all 
workers. His or her productivity, $p_{w f}$, at firm $f$ is then assumed to be log-normally distributed. Thus, $\log$ productivity $P_{w f}$ is assumed to be normally distributed $N\left(A_{w}, h_{p}^{-1}\right)$ centered on $\log$ ability, with precision (reciprocal of variance) $h_{p} \cdot{ }^{2}$ Conditional on ability, the worker's productivity is independently distributed across firms.

In addition, each worker is endowed with a social network offering links to a fixed number of firms. The role of these network connections is simply to offer more information about a worker to those firms to which he or she is connected. In contrast to the prior work by Staiger (1990), the size of this network varies across workers. In particular, we assume a Poisson distribution for the number of ties in the population.

It is important to note that we make no assumptions about particular network structures. This is in contrast to the recent work by Calvo-Armengol and Jackson(2003b, 2003a) where network structure is the primary focus. The model is also agnostic about issues of strong vs. weak ties (Granovetter 1974, Montgomery 1992) or whether the worker is directly connected to the firm or perhaps has second level connections through other individuals (Krauth 2001). Any situation in which firms can learn more about their match with some workers than with others is contained in this set-up.

\subsection{Firms and Wages}

To assign workers to firms, we assume risk neutrality and that firms bid on workers based upon the expected value of the worker to the firm. However, the information available to different firms varies in this model. While ability is assumed to be common knowledge, evidenced by educational level or other public information, a worker's productivity at any given firm is not directly observable by either firms or workers themselves. Instead, the firms to which a worker is connected observe a noisy signal of that productivity. In contrast, "uninformed" firms see only the workers ability.

The signal available to the informed firms is $S_{w f}=P_{w f}+u_{w f}$, where $u_{w f}$ is assumed to be distributed $N\left(0, h_{u}^{-1}\right)$. Given this signal, each "informed" firm $f$ can then estimate the expected productivity at their firm for each worker $w$. With the given distributions for productivity and the

\footnotetext{
${ }^{2}$ We use capital letters to denote the natural logarithms of variables denoted by small letters.
} 
signal, the posterior distribution for productivity is:

$$
P_{w f} \mid S_{w f}, A_{w} \sim N\left(\frac{h_{p} A_{w f}+h_{u} S_{w f}}{h_{p}+h_{u}},\left(h_{p}+h_{u}\right)^{-1}\right)
$$

Firms not linked to individuals also bid in this model. It is likely that a worker involved in searching for work may send a resume or call an employer at which he or she has no individual link. In such a case, the unlinked firm receives no additional signal above and beyond "publicly" available information; therefore, the expected value of the worker is equal to the (publicly known) ability level, $a_{w}$.

To set wages, we first assume that firms bid for workers in a second-price auction. Under the assumption of risk neutrality, this guarantees that firms will bid the mean of the posterior distribution of productivity. To be consistent with a second-price auction, we include at least two uninformed bidders so that workers with zero links to firms still have a second bid.

Actual wages are set at the Nash bargaining solution where the workers and the firms equally split the difference between the highest and second highest bid. This assumption is borrowed from the dynamic search literature, and although it may seem ad hoc in this model, it leads to cleaner results as discussed in the last section. ${ }^{3}$

\section{Simulation}

To analyze the wage patterns generated by our model, we simulate the results. While it may be possible to generate analytic comparative static predictions for the case of fixed ties, the assumption of a distribution of ties in the population makes simulation the preferred method. This numerical approach also allows us to calibrate the model and to make some first pass guesses as to how quantitatively important these effects may be. In this section, we discuss the simulations and their results. A discussion of the calibration is deferred to the next section.

\footnotetext{
${ }^{3}$ The second price auction assumption is convenient but not necessary. Any mechanism that assigns workers to the highest value bidder and sets the wage between the highest and second highest value will yield the same results.
} 


\subsection{Method}

The basic mechanics of our simulations involve two steps. In the first step, we assume a fixed ability for all workers and a distribution of productivity around this mean. We also fix the value for the precision of the signal and vary the number of ties from 1 to 25. Thus for a given iteration (e.g. signal precision $=.1$, ties $=7$ ), we generate productivity values and signals for each individual at each firm.

In the results presented here, we have generated 20,000 workers. Thus in the example, we would generate productivity values at 9 firms for each of the workers (180,000 productivities) and signals at 7 of those firms (140,000 signals). From these productivities and signals, we determine the bids and wages. It is then easy to compute the mean and variance of these, and their logarithms, across all 20,000 workers. This is done for each specification of signal precision and number of ties.

In the second step, we choose various values to describe the distribution of ties in the population. With our assumption that ties are Poisson distributed, we need only pick one parameter, $\lambda$, to describe the distribution. Thus, for each value of $\lambda$ and value of signal variance, we can describe the mean and variance of log income in the population.

To simulate the model, we need values for the four main parameters; the mean and variance of productivity, the variance of the firm's signal and the distribution of ties in the population. To begin, we assume the mean and variance of the logarithm of productivity to be 2.3753 and 0.86559 , respectively. These values are taken from the calibration exercise and are discussed in the next section.

With no empirical data to rely upon, we run all of our simulations at three values for the variance of the signal: $0.00,0.10$, and 0.25 . The first case corresponds to a prefect signal; firms are fully informed of the workers' productivity at their own firm.

To assess the next two cases, consider the perfectly informed employer who sees a signal of 3.306 , one standard deviation above the mean. He or she knows productivity to be roughly $\$ 27,000$ for that worker. In contrast, with a signal variance of .1, the same employer would judge productivity to be just under $\$ 27,000$ with a standard deviation of nearly $\$ 8,000$. In the case of signal variance equal to .25 , the employer would estimate productivity at $\$ 24,000$ with standard deviation of about 
$\$ 11,000$. On their own merits, these numbers seem reasonable. As well, they seem like reasonable benchmarks given that an uninformed firm would estimate productivity with a standard deviation of over $\$ 19,000$.

The last needed parameter is the number of ties. We examine the results of the simulations in two steps, first looking at the distribution of wages for populations with a fixed number of connections, and then examining populations with varying numbers of ties. Thus, in the first set of results, we examine homogeneous populations with 0 to 25 informed bidders. In the second set, we create populations with Poisson distributed numbers of ties ranging from $\lambda$ equal 1 to 8 .

\subsection{Results}

The first set of results is displayed in Table 1, detailing the mean wage, mean output, and the mean and variance of log-wages for various signal variances and level of ties. As expected, the average wage is strictly increasing in the number of ties. This is precisely the result from the model of wages and ties in Montgomery (1991). Individuals with 0 or 1 tie earn of $\$ 16,578$ (the expectation of their productivity) while a worker with five ties will earn nearly double that amount. Obviously, mean log-wages are also monotonically increasing.

An interesting pattern emerges however, among the variance of wages. At the lower end, the variance of wages rises as increasing ties offer more and more workers the chance to earn wages above their productivity. As the number of ties grows however, the variance drops. In the limit, we expect the variance to go to zero as all wages are tending to infinity. This is exactly the pattern we see in Table 1, however it is most apparent in the simulation for a signal variance of 0.25 . Here the variance of log wages increases up to ten ties and then falls over the remaining range.

Table 1 also shows us that very little qualitatively differs as the signal variance is altered. With a very noisy signal, the mean wage is lower as employers are forced to place more weight on the publicly available information and less on their individual signals. The variance is also lower for this same reason.

To assess the role that variation in network size plays in inequality, we examine populations with varying numbers of ties. Each is identified by the Poisson parameter and the results are displayed 
Table 1: Wage Distribution for Fixed Number of Informed Bidders (plus two uninformed bidders)

\begin{tabular}{|c|c|c|c|c|c|c|c|c|c|c|}
\hline & & & & Numb & of $\mathrm{In}$ & rmed $\mathrm{F}$ & dders & & & \\
\hline & 0 & 1 & 2 & 3 & 4 & 5 & 10 & 15 & 20 & 25 \\
\hline Signal Varianc & $=0.00$ & & & & & & & & & \\
\hline Mean Wage & 16.578 & 19.591 & 22.626 & 25.393 & 28.136 & 30.725 & 41.640 & 49.819 & 56.241 & 61.848 \\
\hline Mean Output & 16.722 & 22.373 & 27.840 & 31.924 & 35.882 & 39.374 & 52.817 & 62.233 & 69.471 & 75.933 \\
\hline Mean LogWage & 2.808 & 2.930 & 3.043 & 3.141 & 3.232 & 3.313 & 3.618 & 3.809 & 3.939 & 4.040 \\
\hline Var LogWage & 0.000 & 0.068 & 0.121 & 0.155 & 0.180 & 0.196 & 0.207 & 0.189 & 0.173 & 0.161 \\
\hline Percent Ties & 0.000 & 0.324 & 0.542 & 0.685 & 0.787 & 0.855 & 0.980 & 0.997 & 1.000 & 1.000 \\
\hline Signal Vari & $=0.10$ & & & & & & & & & \\
\hline Mean Wage & 16.578 & 19.084 & 21.606 & 23.906 & 26.178 & 28.315 & 37.238 & 43.816 & 48.914 & 53.307 \\
\hline Mean Output & 16.722 & 22.373 & 27.840 & 31.924 & 35.882 & 39.374 & 52.817 & 62.233 & 69.471 & 75.933 \\
\hline Mean LogWage & 2.808 & 2.915 & 3.016 & 3.103 & 3.184 & 3.257 & 3.530 & 3.702 & 3.819 & 3.909 \\
\hline Var LogWage & 0.000 & 0.053 & 0.094 & 0.121 & 0.141 & 0.154 & 0.164 & 0.150 & 0.137 & 0.128 \\
\hline Percent Ties & 0.000 & 0.324 & 0.542 & 0.685 & 0.787 & 0.855 & 0.980 & 0.997 & 1.000 & 1.000 \\
\hline Signal Vari & $=0.25$ & & & & & & & & & \\
\hline Mean Wage & 16.578 & 18.574 & 20.580 & 22.411 & 24.213 & 25.900 & 32.867 & 37.907 & 41.751 & 45.013 \\
\hline Mean Output & 16.722 & 22.373 & 27.840 & 31.924 & 35.882 & 39.374 & 52.817 & 62.233 & 69.471 & 75.933 \\
\hline Mean LogWage & 2.808 & 2.899 & 2.984 & 3.059 & 3.129 & 3.192 & 3.429 & 3.578 & 3.679 & 3.758 \\
\hline Var LogWage & 0.000 & 0.037 & 0.068 & 0.088 & 0.103 & 0.113 & 0.121 & 0.111 & 0.101 & 0.094 \\
\hline Percent Ties & 0.000 & 0.324 & 0.542 & 0.685 & 0.787 & 0.855 & 0.980 & 0.997 & 1.000 & 1.000 \\
\hline
\end{tabular}

Notes: Simulation results based on 20,000 individuals.

in Table 2. As expected, the average wage is increasing as the average worker is better connected. The variance of log wages also follows the same pattern as above, rising first and then falling.

Our last main result is included on the line labeled Per Var. This value represents the percentage of overall variance in log wages attributable to differences in the number of ties among individuals. It is rather startling to find that roughly $13 \%-15 \%$ of the variation in log wages is from this source. As described earlier, measurable differences among individuals may explain $50 \%$ of the variation in wages. Since all individuals are identical in observable characteristics, this portion of the variation is already ignored. Among the remaining $50 \%$, our model indicates that nearly $1 / 6$ th is attributable to differences in human capital while the remaining portion is the result of variations in the quality of the worker-firm match.

To assess the model, we also examine two other predictions: the difference between output and wages, and the percentage of jobs found through network connections. For low numbers of ties, the level of output per worker is substantially higher than the wage, approximately $25 \%$ higher. The gap lessens somewhat slowly so that the difference is still over $20 \%$ for workers with the highest number of ties. This outcome is the direct result of our assumption that log-wages are normally 
Table 2: Aggregate Wage Distribution by Expected Number of Ties

\begin{tabular}{|c|c|c|c|c|c|c|c|c|c|c|}
\hline & & & & Exp & ted $\mathrm{Nu}$ & nber of & Ties & & & \\
\hline & 1 & 2 & 3 & 3.1965 & 4 & 5 & 5.7211 & 6 & 7 & 8 \\
\hline Signal Varia & $=0.00$ & & & & & & & & & \\
\hline Mean Wage & 19.570 & 22.464 & 25.239 & 25.770 & 27.890 & 30.410 & 32.144 & 32.796 & 35.051 & 37.181 \\
\hline Var LogWage & 0.073 & 0.127 & 0.165 & 0.171 & 0.192 & 0.210 & 0.218 & 0.220 & 0.226 & 0.228 \\
\hline Percent Var & 0.171 & 0.163 & 0.155 & 0.154 & 0.148 & 0.140 & 0.135 & 0.133 & 0.125 & 0.118 \\
\hline Percent Ties & 0.276 & 0.475 & 0.619 & 0.642 & 0.723 & 0.798 & 0.840 & 0.853 & 0.893 & 0.922 \\
\hline Signal Vari & $=0.10$ & & & & & & & & & \\
\hline Mean Wage & 19.065 & 21.469 & 23.769 & 24.209 & 25.961 & 28.038 & 29.465 & 30.000 & 31.848 & 33.589 \\
\hline Var LogWage & 0.057 & 0.099 & 0.130 & 0.134 & 0.151 & 0.165 & 0.172 & 0.174 & 0.179 & 0.180 \\
\hline Percent Var & 0.173 & 0.165 & 0.157 & 0.156 & 0.150 & 0.142 & 0.137 & 0.135 & 0.127 & 0.120 \\
\hline Percent Ties & 0.276 & 0.475 & 0.619 & 0.642 & 0.723 & 0.798 & 0.840 & 0.853 & 0.893 & 0.922 \\
\hline Signal Varic & 0.25 & & & & & & & & & \\
\hline Mean Wage & 18.558 & 20.469 & 22.294 & 22.642 & 24.028 & 25.666 & 26.788 & 27.208 & 28.656 & 30.015 \\
\hline Var LogWage & 0.041 & 0.071 & 0.094 & 0.098 & 0.110 & 0.121 & 0.126 & 0.127 & 0.131 & 0.133 \\
\hline Percent Var & 0.175 & 0.167 & 0.160 & 0.158 & 0.152 & 0.145 & 0.139 & 0.137 & 0.129 & 0.122 \\
\hline Percent Ties & 0.276 & 0.475 & 0.619 & 0.642 & 0.723 & 0.798 & 0.840 & 0.853 & 0.893 & 0.922 \\
\hline
\end{tabular}

Notes: Simulation results based on 20,000 individuals.

distributed, the properties of order statistics on normal variables, and our assumption that workers and firms split the difference in the two highest bids. With low numbers of draws the differences between the first and second order statistics of normal variables are quite large leading to this apparent anomaly. The assumption of one-half for the Nash bargaining parameter mitigates this result, but still leaves a large gap between wages and output.

The percentage of jobs found through network ties is detailed on the line labeled "Percent Ties" in Table 2. For populations with an average of three or four ties, the model predicts that roughly $60 \%$ of jobs are filled by workers who used informal contacts. This is a bit higher than, although consistent with, the empirical values from many of the studies previously cited. The percentage rises as the number of ties in the population rises, and at the extremes all jobs are found this way.

\section{Calibration}

In order to perform the simulations above, we needed values for the parameters of the productivity distribution. In order to obtain these, we chose to calibrate the model to some existing data. To emphasize the role of limited connections, we will use separate wage distributions for blacks and whites but assume that the "objective" conditions, the mean and variance of productivity, are 
the same for both groups. They differ only in the distribution of ties. More precisely, we ask the following question: Given no signal noise, what values for the mean and variance of log productivity and for the distribution of ties for Blacks and Whites, will yield a distribution resembling an empirical distribution that we chose? In other words, can we find reasonable values for the four free parameters that will generate the 'true' wage patterns for these two populations?

\subsection{Method}

To do this, we first chose the population to be 24-39 year-old men who completed high school but had no college education and who worked full time for 50-52 weeks during the year. We strove for as homogeneous a group as we could get data on in order to let the model explain the remaining variation. Data from the March 1999 Current Population Survey indicates that 1998 average earnings for whites in this group was approximately $\$ 31,804$ with a standard deviation of roughly $\$ 17,804$. For similar black workers, the average wage and standard deviation were $\$ 25,322$ and $\$ 10,967$, respectively. These values as well as the mean and variance of log wages are detailed in Table $3 .^{4}$

Table 3: Empirical Distribution of Wages (000's)

$\begin{array}{lcccc} & \text { Mean Wage } & \text { SD Wage } & \text { Avg LnWage } & \text { Var LnWage } \\ \text { White } & 31.804 & 17.804 & 3.348 & 0.2179 \\ \text { Black } & 25.322 & 10.967 & 3.145 & 0.1714\end{array}$

Notes: Values from 1999 March Supplement to the Current Population Survey. Observations with wages below $\$ 9,000$ were exlcuded from the calculation.

To perform the calibrations, we use a polytope search method over this four dimensional space (mean and variance of $\log$ productivity, $\lambda_{w}$ and $\lambda_{b}$ ). Since we are targeting four values i.e. mean and variance of log wages for Blacks and Whites, we inherently have a system of four non-linear equations in four unknowns. From this, we create the distance function equal to the Cartesian distance from each of these equations' results to the targets and we search for any zeros for this function. Since this search method will converge to any local minima, we grid search over a wide

\footnotetext{
${ }^{4}$ Chandra (2000) details the persistent racial gap in earnings. While the author also cautions researchers examining this issue to examine jointly wages and employment, in this context an examination of differences among employed workers is the correct framework.
} 
range of reasonable values.

\subsection{Results}

The only minimum found over the searched grid exist at the values listed in Table 4 . These are precisely the values used to perform the simulations in the previous section.

Table 4: Calibrated Parameters

$\begin{array}{ll}\text { Mean Ability } & 2.3753 \\ \text { Variance of Productivity } & 0.8656 \\ \lambda_{w} & 5.7211 \\ \lambda_{b} & 3.1965\end{array}$

The question that remains is whether the number of ties in these simulations is reasonable. While there is little direct evidence on this point, there is some prior empirical work. In 1985, the General Social Survey included questions regarding the social networks of individuals. As Marsden (1987) describes, the 'GSS network data concern those persons with whom a respondent "discusses important matters", whether these be family, finances, health, politics, recreation or other things.' As such, it is hard to say that this is a broader or narrower network definition than we would like. Given the inclusion of the word 'important', it is easy to believe that this name generator would lean toward strong ties of a reasonably intimate matter, a view shared by Marsden. However, given

any lack of specificity regarding what matters one discusses with these individuals, the list may be overly broad. For now, we use it as a first benchmark in our analysis.

In Marsden's study, the average size of the network was 3.01, with roughly half of these individuals being kin. These size of the networks do not vary much by gender, but do vary by race and education. Average network size is highest for Whites (3.01) and lowest for Blacks (2.25) and these values are not far from the values we find, 5.7 and 3.2 respectively.

\section{Conclusion}

Since De Schweinetz' (1932) early study of full-fashion hosiery workers in 1930, we have known about the importance of social connections in the labor matching process. The results above 
logically extend that result and indicate that not only does this feature alone introduce disparities among otherwise similar workers, but that disparities in these networks engender further inequality. In fact, the magnitude of these effects may be as large as many of the more traditional explanations for differences in wages.

This finding furthers the argument for considering social capital when studying inequality and for the explicit inclusion of an individual's information network as a major component of that capital. In a recent symposium, both Loury (1998) and Arrow (1998) point to this direction, and the results this paper provide evidence that such endeavors are likely to payoff. 


\section{References}

Arrow, Kenneth J., "What has Economics to Say about Racial Discrimination," Journal of Economic Perspectives, Spring 1998, 12 (2), 91-100.

Bewley, Truman F., Why Wages Don't Fall During a Recession, Harvard University Press, 1999.

Calvo-Armengol, Antonio and Matthew O. Jackson, "Networks in Labor Markets: Wage and Employment Dynamics and Inequality," April 2003. mimeo.

and ___ , "Social Networks in Determining Employment: Patterns, Dynamics, and Inequality," April 2003. mimeo.

Chandra, Amitabh, "Labor-Market Dropouts and the Racial Wage Gap: 1940-1990," American Economic Review, May 2000, 90 (2), 333-338.

Datcher, Linda, "The Impact of Informal Networks on Quit Behavior," Review of Economics and Statistics, August 1983, 65 (3), 491-495.

Granovetter, Mark S., Getting A Job: A Study of Contacts and Careers, Cambridge, MA: Harvard University Press, 1974.

Green, Gary Paul, Leann M. Tigges, and Daniel Diaz, "Racial and Ethnic Differences in Job-Search Strategies in Atlanta, Boston, and Los Angeles," Social Science Quarterly, June $1999,80(2), 263-278$.

Holzer, Harry J., "Informal Job Search and Black Youth Unemployment," American Economic Review, May 1987, 77 (3), 446-452.

Jencks, Christopher et al., Inequality: A reassessment of the effect of family and schooling in America, New York, NY: Basic Books, 1972.

Krauth, Brian, "A Dynamic Model of Job Networking and Persistent Inequality," December 2001. mimeo, Simon Fraser University. 
Loury, Glenn C., "Discrimination in the Post-Civil Rights Era: Beyond Market Interactions," Journal of Economic Perspectives, Spring 1998, 12 (2), 117-126.

Marsden, Peter V., "Core Discussion Networks of Americans," American Sociological Review, February 1987, 52 (1), 122-131.

Montgomery, James D., "Social Networks and Labor-Market Outcomes: Toward an Economic Analysis," American Economic Review, 1991, 81 (5), 1408-1418.

, "Job Search and Network Composition: Implications of the Strength-of-Weak-Ties Hypothesis," American Sociological Review, 1992, 57 (5), 586-596.

__ ,Weak Ties, Employment, and Inequality: An Equilibrium Analysis," American Journal of Sociology, 1994, 99 (5), 1212-1236.

Myers, Charles A. and George P. Shultz, The Dynamics of a Labor Market, New York: Prentice-Hall, Inc., 1951.

Pistaferri, Luigi, "Informal Networks in the Italian Labor Market," Giornale degli Economisti e Annali di Economia, December 1999, 58 (3-4), 355-375.

Rees, Albert, "Information Networks in Labor Markets," American Economic Review, 1966, 56 (May), 559-566.

and George P. Shultz, Workers and Wages in an Urban Labor Market, Chicago and London: The University of Chicago Press, 1970.

Schweinetz, Dorothea De, How Workers Find Jobs: A Study of Four Thousand Hosiery Workers in Philadelphia, Philadelphia: University of Pennsylvania Press, 1932.

Simon, Curtis J. and John T. Warner, "Matchmaker, Matchmaker: The Effect of Old Boy Networks on Job Match Quality, Earnings, and Tenure," Journal of Labor Economics, July 1992, $10(3), 306-330$. 
Staiger, Doug, "the Effect of Connections on the Wages and Mobility of Young Workers," March 1990. mimeo, MIT. 


\section{A Appendix}

Below we detail the partition for the variance of wages into the part attributable to differences in the level of ties and the part from differences in draws among workers with same size networks.

$$
\begin{aligned}
\operatorname{Var}\left(w_{i}\right) & =E\left(w_{i}^{2}\right)-\left[E\left(w_{i}\right)\right]^{2} \\
& =\frac{1}{N} \sum_{i=1} w_{i}^{2}-\bar{w}^{2} \\
& =\frac{1}{N} \sum_{i=1}^{N} w_{i}^{2}-\frac{2}{N} \sum_{t=1}^{T} \bar{w}_{t} \sum_{i=1}^{N_{t}} w_{i}^{t}+\frac{1}{N} \sum_{t=1}^{T} \bar{w}_{t} \sum_{i=1}^{N_{t}} w_{i}^{t}+\frac{1}{N} \sum_{t=1}^{T} \bar{w}_{t} \sum_{i=1}^{N_{t}} w_{i}^{t}-\bar{w}^{2} \\
& =\frac{1}{N} \sum_{i=1}^{N} w_{i}^{2}-\frac{2}{N} \sum_{t=1}^{T} \bar{w}_{t} \sum_{i=1}^{N_{t}} w_{i}^{t}+\frac{1}{N} \sum_{t=1}^{T} \bar{w}_{t}\left(N_{t} \bar{w}_{t}\right)+\frac{1}{N} \sum_{t=1}^{T} \bar{w}_{t}\left(N_{t} \bar{w}_{t}\right)-2 \bar{w}^{2} \frac{1}{N} \sum_{t=1}^{T} N_{t} \bar{w}^{2} \frac{1}{N} \sum_{t=1}^{T} N_{t} \\
& =\frac{1}{N} \sum_{t=1}^{T} \sum_{i=1}^{N_{t}}\left(w_{i}^{t}\right)^{2}-\frac{2}{N} \sum_{t=1}^{T} \sum_{i=1}^{N_{t}} \bar{w}_{t} w_{i}^{t}+\frac{1}{N} \sum_{t=1}^{T} \sum_{i=1}^{N_{t}} \bar{w}_{t}^{2}+\frac{1}{N} \sum_{t=1}^{T} N_{t} \bar{w}_{t}^{2}-\frac{2}{N} \sum_{t=1}^{T} N_{t} \bar{w} \bar{w}_{t}+\frac{1}{N} \sum_{t=1}^{T} N_{t} \bar{w}^{2} \\
& =\frac{1}{N} \sum_{t=1}^{T} \sum_{i=1}^{N_{t}}\left(\left(w_{i}^{t}\right)^{2}-2 \bar{w}_{t} w_{i}+\bar{w}_{t}^{2}\right)+\frac{1}{N} \sum_{t=1}^{T} N_{t}\left(\bar{w}_{t}^{2}-2 \bar{w} \bar{w}_{t}+\bar{w}^{2}\right) \\
& =\frac{1}{N} \sum_{t=1}^{T} \sum_{i=1}^{N_{t}}\left(w_{i}^{t}-\bar{w}_{t}\right)^{2}+\frac{1}{N} \sum_{t=1}^{T} N_{t}\left(\bar{w}_{t}-\bar{w}\right)^{2} \\
& =\sum_{t=1}^{T} \frac{N_{t}}{N} \frac{1}{N_{t}} \sum_{i=1}^{N_{t}}\left(w_{i}^{t}-\bar{w}_{t}\right)^{2}+\sum_{t=1}^{T} \frac{N_{t}}{N}\left(\bar{w}_{t}-\bar{w}\right)^{2} \\
& =\sum_{t=1}^{T} p_{t} v a r\left(w_{t}\right)+\sum_{t=1}^{T} p_{t}\left(\bar{w}_{t}-\bar{w}^{2}\right. \\
& \\
&
\end{aligned}
$$

